\title{
Activities of the Society
}

\begin{abstract}
Titles of the reports presented by the members of The Electrochemical Society of Japan at the Fall Meeting under the auspieces of The Electrochemical Society of Japan in corporation with other chemical societies and associations in Japan held at Tokyo University on Oct. 8, 1966.
\end{abstract}

Studies on thermogalvanic Corrosion of Copper in Alkaline Solutions. By Hiroshi Hirashima, Tomiya Kishi, Takashi Nagai and Takeshi Takei.

Time-Variation of Anodic Polarization Curve of Nickel in Sulfuric Acid Solution. by Minari Goto, Norio Sato and Go Okamoto.

The Electrochemical Behavior of Passive Film on Chromium-Iron Alloy. By Masaru Okuyama, Shiro Haruyama and Masao Mukai.

Dissolution Behavior of Stainless Steel in Hydrochloric Acid. By Takasi Nakane, Takasi Sazi and Masao Mukai.

Study on Tin Electrolytic Refining using Amalgamation Process (part 2).Electrolytic Dissolution Behavior of Tin Amalgam Anode. By Nobuyuki Koura and Masao Mukai.

Electrochemical Properties of Rhodium. By Tomihiko Okamura.

Chlorine Electrode Reaction of Platinum, Palladium and rhodium by Potential Sweep Method. By Masao Takahashi, Toshio Okazima and Mizuo Tanaka. Formation of Titanium Nitride by Use of a Transferred Plasma Torch. By Osamu Matsumoto.

The Effects of Chlorin Pressure on Absorption Spectra in Molten Silver Chloride. By Tomoo Kirihara, Michio Iseki.

Studies on Liquid-State Electronic Elements in Molten Salts (part 2). By Takashi Mukaibo and Shunji Asakura.

Anodic Passivation of Platimum, Palladium and Rhodium in Fused Chloride Containing Oxide Anion. By Yasushi Kanzaki and Masao Takahashi.

Studies on the Refining of Aluminium-densities of the Fused Electrolytes. By Kentaro Taniuchi and Toshihiko Sato.

Studies on the Electrochemical Behaviours of the Molten $\mathrm{AlCl}_{3}$-Alkali Chlorides Systems (part 1). Vapor Pressure of the Molten $\mathrm{AlCl}_{3}-\mathrm{NaCl}$ Systems. By Toshio Narita, Rinzo Midorikawa and Tatsuo Ishikawa.

Studies on the Electrometallurgy of in the Fused Salts (part 3). Equilibrium Electrode Potentials of $\mathrm{CaCl}_{2}-\mathrm{CaO}-\mathrm{TiO}_{2}$ Systems. By Rinzo Midorikawa and Kinji Kato. 


\title{
THE 34TH MEETING \\ of \\ THE ELECTROCHEMICAL SOCIETY OF JAPAN
}

\author{
Aoyama Gakuin University, Tokyo \\ March 28 and 29, 1967
}

Sessions will be scheduled on Theoretical Electrochemistry, and Applied Physical Chemistry, Electroorganic, Electroanalysis, Electrodeposition and Surface Treatment, Industrial Electrolytic Batteries, Corrosion and Prevention, Electronics and Materials for Electrical Industry, Extractive Metallurgy, High Temperature Chemistry and Fused Salts, Electricidischarge Chemistry and Radiation Chemistry, and Instrumentation and Quality Control.

Tuesday, March 28, 1967, 9:00 a.m. - Conference and Invited Lectures Wednesday, March 29, 1967, 9:00 a.m. - Conferences and Discussion

Thursday, March 30, 1967 -

Informalmeeting and Excursion

Papers are now being solicited for the 34th Meeting. Duplicate copies of the 200-words abstract are due at Society Headquarters, 3,1-chome, Yuraku-cho, Tokyo, not later than Feb. 21, 1967 in order to be included in the program. Please indicate the tirle-followed by the author's name and business or university connection and underline the name of the author who will be present at the conference.

Further information will be available from Headquarters, 3, 1-chome, Yurakucho, Chiyodaku, Tokyo. 